\title{
Deciphering the molecular mechanisms of epitranscriptome regulation in cancer
}

\author{
Seung Hun Han $^{1,2,3}$ E Junho Choe $e^{1,2,3, *}$ \\ ${ }^{1}$ Department of Life Science, College of Natural Sciences, Hanyang University, Seoul 04763, ${ }^{2}$ Research Institute for Natural Sciences, \\ Hanyang University, Seoul 04763, ${ }^{3}$ Research Institute for Convergence of Basic Sciences, Hanyang University, Seoul 04763, Korea
}

Post-transcriptional regulation is an indispensable cellular mechanism of gene expression control that dictates various cellular functions and cell fate decisions. Recently, various chemical RNA modifications, termed the "epitranscriptome," have been proposed to play crucial roles in the regulation of post-transcriptional gene expression. To date, more than 170 RNA modifications have been identified in almost all types of RNA. As with DNA modification-mediated control of gene expression, regulation of gene expression via RNA modification is also accomplished by three groups of proteins: writers, readers, and erasers. Several emerging studies have revealed that dysregulation in RNA modification is closely associated with tumorigenesis. Notably, the molecular outcomes of specific RNA modifications often have opposite cellular consequences. In this review, we highlight the current progress in the elucidation of the mechanisms of cancer development due to chemical modifications of various RNA species. [BMB Reports 2021; 54(2): 89-97]

\section{INTRODUCTION}

Over the past few decades, it has been established that genetic dysregulation underlies various human diseases. For example, genetic errors arising from gene amplification, deletion, mutation, or chromosomal translocation have been associated with numerous cancers (1-3). Meanwhile, increasing evidence suggests that epigenetic modifications of chromatin structure also affect tumor formation and cancer development via abnormal regulation of gene expression (4). Furthermore, the impairment of epigenetic regulation of oncogenes and tumor suppressor genes has been linked to several signaling pathways that lead

*Corresponding author. Tel: +82-2-2220-0966; Fax: +82-2-2298-0319; E-mail: jcho2711@hanyang.ac.kr

https://doi.org/10.5483/BMBRep.2021.54.2.212

Received 11 September 2020, Revised 13 October 2020, Accepted 25 November 2020

Keywords: Cancer, Epitranscriptomics, Gene expression, Post-transcriptional regulation, RNA modification to cancer development (5-7). Similarly, several recent studies have suggested an important role for RNA modifications, termed the "epitranscriptome", representing a new layer of post-transcriptional gene regulation $(8,9)$. Although several studies have investigated signaling pathways and transcriptional regulation in cancer, relatively little is known about the post-transcriptional regulation of cancer. Therefore, a better understanding of the gene regulatory mechanisms controlling tumorigenesis and cancer development will facilitate their therapeutic exploitation $(10,11)$.

To date, more than 170 chemical RNA modifications have been identified, including $N 6$-methyladenosine $\left(\mathrm{m}^{6} \mathrm{~A}\right)$, pseudouridine $(\psi), N 1$-methyladenosine $\left(\mathrm{m}^{1} \mathrm{~A}\right), 2^{\prime}$-O-methylation $(\mathrm{Nm})$, $\mathrm{N} 5$-methylcytosine $\left(\mathrm{m}^{5} \mathrm{C}\right)$, and internal N7-methylguanosine $\left(m^{7} G\right)(12,13)$. Each of these modifications has been shown to have a preferential modification site within the mRNA.

Similar to DNA methylation in epigenetics, three classes of RNA-binding proteins, broadly classified as writers, readers, and erasers, mediate the regulation of RNA modification (Fig. 1) (14). Writer proteins install the modification, while eraser proteins remove the modification, and reader proteins recognize the modification and regulate the metabolism of the target RNA. The discovery of both writer and eraser proteins indicates that many RNA modifications are likely reversible. Many recent studies have suggested that abnormally regulated RNA modification may lead to tumorigenesis and cancer development $(2$, $15,16)$.

\section{VARIOUS RNA MODIFICATIONS DRIVE TUMORIGENESIS}

In this review, we focus on six internal RNA modifications most closely linked to tumorigenesis and discuss the RNA species in which they have been identified, their molecular mechanisms, and evidence of their involvement in cancer (Fig. $1)$.

\section{N6-methyladenosine $\left(m^{6} A\right)$}

N6-methyladenosine $\left(\mathrm{m}^{6} \mathrm{~A}\right)$ is one of the best-characterized RNA modifications whose importance has recently been highlighted in various biological studies. $\mathrm{m}^{6} \mathrm{~A}$ modification has been identified in several RNA species, including messenger 


\begin{tabular}{|c|c|c|c|c|c|c|c|}
\hline \multicolumn{2}{|c|}{ Modification } & $\mathbf{m}^{6} \mathrm{~A}$ & $\psi$ & $\mathbf{m}^{1} \mathbf{A}$ & $\mathrm{Nm}$ & $\mathrm{m}^{5} \mathrm{C}$ & $m^{7} \mathbf{G}$ \\
\hline \multicolumn{2}{|c|}{ Structure } & $\mathrm{OH} \mathrm{OH}_{\mathrm{OH}}$ & $\sum_{\mathrm{OH}}^{\mathrm{OH}}$ & $\mathrm{OH} \mathrm{OH}_{1}$ & $\sum_{\mathrm{OH} \quad \mathrm{OCH}_{3}}$ & $\mathrm{OH} \mathrm{OH}$ & $\underbrace{}_{\mathrm{OH} \mathrm{OH}}$ \\
\hline \multicolumn{2}{|c|}{ Writer } & METTL3/METTL14 & PUSs(1-10), DKC1 & TRMT6/TRMT61A & FTSJ1, FTSJ2, FBL & $\operatorname{NSUNs}(1-7), \operatorname{TRDMT} 1$ & METTL1MDR4 \\
\hline \multicolumn{2}{|c|}{ Eraser } & FTO, ALKBH5 & NR & ALKBH1, ALKBH3 & NR & NR & NR \\
\hline \multicolumn{2}{|c|}{ Reader } & $\begin{array}{l}\text { YTHDFs }(1-3), \text { YTHDCs }(1,2) \\
\text { IGF2BPs(1-3), hnRNPC } \\
\text { hnRNPG, elF3, METTL3 }\end{array}$ & NR & YTHDF2, YTHDF3 & NR & Aly/REF, YBX1 & NR \\
\hline \multirow{2}{*}{$\begin{array}{l}\text { Molecular } \\
\text { function }\end{array}$} & mRNA & $\begin{array}{l}\text { Splicing, Export, } \\
\text { Translation, Stability }\end{array}$ & NR & Stability & NR & Export, Stability & NR \\
\hline & ncRNA & Processing, Stability & Processing, Stability & Processing & Translation & Stability & Processing \\
\hline \multicolumn{2}{|c|}{ RNA species } & $\begin{array}{c}\text { mRNAs }(34-43,45,46), \\
\text { miR221/222 miRNA (44), } \\
\text { LINC00958 lincRNA (15), } \\
\text { XIST IncRNA (47) }\end{array}$ & 18S rRNA (61) & $\begin{array}{l}\text { tRNA } \\
\text { tRet (67), } \\
\text { tRNA-derived small RNAs (70) }\end{array}$ & rRNAs (80) & HDGF mRNA (89) & let-7e miRNA $(93,97)$ \\
\hline \multicolumn{2}{|c|}{ Positive regulation } & $\begin{array}{c}\text { Gastric Cancer (40), CRC (41), } \\
\text { HCC (15), Lung Cancer (34, 35), } \\
\text { BLC (42, 44) }\end{array}$ & $\operatorname{BrC}(55), \operatorname{PC}(56,59), \operatorname{HCC}(57)$ & GBM (67) & $\operatorname{PC}(78), \operatorname{BrC}(79,80)$ & $\begin{array}{c}\text { Squamous-Cell Carcinoma (85), } \\
\text { BLC (89) }\end{array}$ & $\operatorname{HCC}(6)$ \\
\hline \multicolumn{2}{|c|}{ Negative regulation } & $\operatorname{CRC}(45,47), \operatorname{BLC}(46)$ & $\operatorname{BrC}(60), \operatorname{HCC}(61)$ & $\mathrm{HCC}, \mathrm{PC}(70)$ & NR & NR & $\begin{array}{l}\text { Lung Cancer (93), } \\
\text { Colon Cancer (97) }\end{array}$ \\
\hline
\end{tabular}

Fig. 1. Role of RNA modification in cancer. Six representative cancer-associated RNA modifications are listed with their chemical structures, molecular functions, target RNA species, and binding proteins. Positive or negative regulation indicates the correlation between each RNA modification and the corresponding cancer progression. Blue boxes indicate general information about each RNA modification regardless of cancer association, while the yellow boxes represent information about RNA modification dependent-cancer regulation. NR, not reported.

RNA (mRNA), transfer RNA (tRNA), ribosomal RNA (rRNA), non-coding RNA (ncRNA), and viral RNA genomes $(12,17)$. It has been reported that $\mathrm{m}^{6} \mathrm{~A}$ modification is the most prevalent mRNA modification, and approximately $25 \%$ of eukaryotic mRNAs harbor at least one $\mathrm{m}^{6} \mathrm{~A}$ modified base $(8,18)$. Although $\mathrm{m}^{6} \mathrm{~A}$ modification sites vary among different mRNA species and tissues, these sites have been shown to be generally located near translation stop codons in the $3^{\prime}$ untranslated region (UTR) of mRNA $(8,18,19)$. However, a study showed that $\mathrm{m}^{6} \mathrm{~A}$ modifications in ncRNA are dispersed across the gene body without any apparent preferred location (20). Nevertheless, both coding and ncRNAs share a common set of $\mathrm{m}^{6} \mathrm{~A}$ writer protein complexes. Methyltransferase-like protein 3 (METTL3, also known as MT-A70), which catalyzes $\mathrm{m}^{6} \mathrm{~A}$ modification, forms a catalytic core complex with METTL14, which recognizes the DRACH motif $(D=A, G$, or $U$; $R=G$ or $A$; and $\mathrm{H}=\mathrm{A}, \mathrm{C}$, or $\mathrm{U})(18,21)$. Although several different components of the complex have been discovered, most reports consistently suggested that additional proteins, which lack methyltransferase activity, are required for proper $\mathrm{m}^{6} \mathrm{~A}$ modification (22-24). $\mathrm{m}^{6} \mathrm{~A}$ modification is known to be reversed by the action of $\mathrm{m}^{6} \mathrm{~A}$ eraser proteins. Unlike $\mathrm{m}^{6} \mathrm{~A}$ writer protein complexes, only two $\mathrm{m}^{6} \mathrm{~A}$ eraser proteins, fat mass and obesity-associated protein (FTO) and $\alpha$-ketoglutarate-dependent dioxygenase alk B homolog 5 (ALKBH5), have been identified to date $(25,26)$. These two eraser proteins do not form a complex but are independently responsible for demethylation of $\mathrm{m}^{6} \mathrm{~A}(25,26)$. While several previous studies have reported that FTO depletion leads to global demethylation of $\mathrm{m}^{6} \mathrm{~A}$, more recent data indicate that FTO preferentially demethylates $2^{\prime}$-O-dimethyladenosine $\left(\mathrm{m}^{6} \mathrm{Am}\right)$ or $\mathrm{N} 1$-methyladenosine $\left(\mathrm{m}^{1} \mathrm{~A}\right)$ in tRNA (27). In contrast, ALKBH5 is considered a better $\mathrm{m}^{6} \mathrm{~A}$ demethylase candidate as it recognizes the $\mathrm{m}^{6} \mathrm{~A}$ demethylation consensus sequence (26). The $\mathrm{m}^{6} \mathrm{~A}$ reader proteins have been studied more extensively. $\mathrm{m}^{6} \mathrm{~A}$ modification is recognized by proteins belonging to the YT521-B homology (YTH) domain family (YTHDF1, YTHDF2, and YTHDF3), YTH domain-containing proteins (YTHDC1 and YTHDC2), heterogeneous nuclear ribonucleoproteins (hnRNPC and hnRNPG), and insulin-like growth factor 2 mRNA-binding proteins (IGF2BP1, IGF2BP2, and IGF2BP3), which regulate almost all the steps of mRNA metabolism, including splicing, export, translation, and stability (28-32). Interestingly, eukaryotic translation initiation factor 3 (elF3) has also been shown to function as an $\mathrm{m}^{6} \mathrm{~A}$ reader protein by directly binding $\mathrm{m}^{6} \mathrm{~A}$ modification sites in the $5^{\prime}$ UTR of mRNA, resulting in the recruitment of the 435 complex and initiation of translation independently of the cap-binding protein, elF4E (33-35).

Several studies have investigated the association between $\mathrm{m}^{6} \mathrm{~A}$ modification and cancer. These studies have revealed that the levels of $\mathrm{m}^{6} \mathrm{~A}$ mRNA modification in cancer cells are generally elevated and closely correlated with the develop- 
ment of several cancers (36-39). In colorectal cancer (CRC) and gastric cancer, for example, a high degree of $\mathrm{m}^{6} \mathrm{~A}$ modification is associated with mRNA stability $(40,41) . \mathrm{m}^{6} \mathrm{~A}$ reader proteins, IGF2BP1, IGF2BP2, and IGF2BP3, recognize $\mathrm{m}^{6} \mathrm{~A}$ modifications in oncogene mRNAs, preventing mRNA degradation and ultimately promoting cancer development $(40,41)$. In bladder cancer (BLC) and lung cancer, $\mathrm{m}^{6} \mathrm{~A}$ modification increases the translation efficiency of oncogenes without affecting mRNA abundance $(34,35,42)$. Integrin alpha-6 (ITGA6) mRNA exhibits a high level of $\mathrm{m}^{6} \mathrm{~A}$ modification at the $3^{\prime}$ UTR of $\mathrm{mRNA}$, which is recognized by the reader proteins, YTHDF1 and YTHDF3 in BLC, promoting the translation of ITGA6 mRNA (42). In lung cancer, METTL3 has been shown to function as both an $\mathrm{m}^{6} \mathrm{~A}$ writer and a reader protein. METTL3 recognizes $\mathrm{m}^{6} \mathrm{~A}$ modifications at the $3^{\prime}$ UTR of mRNAs near the translation stop codon and then interacts directly with elF3 subunit $\mathrm{h}$ (elF3h) at the $5^{\prime}$ end, promoting translation via ribosome recycling by forming an mRNA loop. Consequently, METTL3-dependent translation enhancement of a large subset of mRNAs triggers tumorigenesis in lung cancer $(34,35)$. Many studies have revealed a correlation between high levels of $\mathrm{m}^{6} \mathrm{~A}$ mRNA modifications and development of several cancers, including acute myeloid leukemia (AML), lung cancer, breast cancer $(\mathrm{BrC}), \mathrm{BLC}$, and glioblastoma $(\mathrm{GBM})(36,38,39$, 43). However, the $m^{6} A$ reader proteins involved in specific cancers and their molecular mechanisms are yet to be elucidated.

Cancer development has also been reported to be influenced by $\mathrm{m}^{6} \mathrm{~A}$ modification of ncRNA $(15,44)$. MicroRNA (miRNA) $\mathrm{m}^{6} \mathrm{~A}$ modification can alter the abundance of miRNA in cells, which in turn regulates the stability of the target mRNA associated with tumorigenesis in BLC and hepatocellular carcinoma (HCC) $(15,44)$. Specifically, METTL3 has been shown to interact with the microprocessor protein, DGCR8, affecting primary-miRNA (pri-miRNA) processing in BLC (44). A study showed that the knockdown of METTL3 in BLC induces the accumulation of pri-miR221/222, whereas the overexpression of METTL3 increases the level of mature miR221/222 (44). The study further showed that METTL3 accelerates the maturation of pri-miR221/222, resulting in the suppression of the transcription of a tumor suppressor gene, phosphatase and tensin homolog (PTEN) (44). In addition, $\mathrm{m}^{6} \mathrm{~A}$ modification of long intergenic non-coding RNA (lincRNA) has been implicated in cancer development. In HCC, METTL3mediated $\mathrm{m}^{6} \mathrm{~A}$ modification increases LINC00958 stability (15). Consequently, accumulation of LINC00958 acts as an miRNA sponge by binding and inhibiting miR-3619-5p. The loss of miR-3619-5p enhances the expression of its target oncogene, hepatoma-derived growth factor (HDGF) mRNA, which in turn promotes lipogenesis, cell proliferation, and migration in HCC cells (15).

However, it has been reported that a high level of $\mathrm{m}^{6} \mathrm{~A}$ modifications may also be inhibitory in the same types of cancer, depending on the target mRNAs. Recently, low levels of $\mathrm{m}^{6} \mathrm{~A}$ modifications were identified in CRC and BLC (45-47). Mechanistically, the increase in $\mathrm{m}^{6} \mathrm{~A}$ modification induced by the overexpression of METTL14 is thought to lead to rapid YTHDF2-mediated mRNA degradation of the essential developmental transcription factor, SRY-related high-mobility-group box 4 (SOX4). Loss of SOX4 expression inhibits CRC malignancy via SOX4-mediated epithelial-mesenchymal transition (EMT) and PI3K/Akt signal transduction (45). In BLC, METTL14 expression is low, resulting in low $\mathrm{m}^{6} \mathrm{~A}$ modification levels. This, in turn, leads to increased mRNA stability of Notch1, which has been shown to play a crucial role in cell proliferation, self-renewal, and metastasis of BLC (46).

The development of several cancers is also influenced by $\mathrm{m}^{6} \mathrm{~A}$ modification of ncRNA. In CRC, an oncogenic long noncoding RNA (IncRNA), the $X$ inactive-specific transcript (XIST), has been shown to be highly methylated and degraded by YTHDF2 (47). Thus, $m^{6} A$-modification-mediated loss of XIST expression leads to the inhibition of cell proliferation, metastasis, and tumorigenesis (47).

\section{Pseudouridine $(\psi)$}

Pseudouridine (also known as 5-ribosyluracil or $\psi$ ) was first discovered in the early 1950 s (48). Initially identified in tRNA and rRNA, pseudouridine has also been found in mRNA, IncRNA, and small nuclear RNA (snRNA) $(49,50)$. Pseudouridine is the most abundant RNA modification occurring in tRNAs and rRNAs (50). In tRNAs, pseudouridine is generally localized to the anticodon stem-loop in the D stem, and to the nucleotide position 55 in the T loop, and thus contributes to the stabilization of the tertiary structure of tRNA (51). Pseudouridines are generated post-transcriptionally via C5-ribosyl isomerization of one or a few target uridines catalyzed by pseudouridine synthases (PUSs) (52). PUSs employ two mechanisms of pseudouridine modification: guide RNA-dependent H/ACA box small nucleolar RNA (snoRNA) and guide RNA-independent pseudouridylation. In guide RNA-dependent pseudouridylation, the H/ACA box snoRNA forms a complex with dyskerin pseudouridine synthase 1 (DKC1), which recognizes specific sequences for pseudouridylation on target RNAs, including rRNA, snRNA, and snoRNA (53). In contrast, in guide RNA-independent pseudouridylation, modification of the target RNA is directly catalyzed by stand-alone PUSs (54). PUS enzymes are classified into six families: TruA, TruB, TruD, RluA, RsuA, and Pus10 (54). PUS1, which belongs to the TruA family, was originally thought to pseudouridylate tRNA alone; however, recent studies have identified that PUS1 also pseudouridylates rRNA, snRNA, and mRNA $(49,50)$. In addition, PUS4 and PUS7 were found to target mRNAs for pseudouridylation in HEK293T cells (50).

Unlike other known RNA modifications, neither reader nor eraser proteins for pseudouridine have been identified to date. Moreover, the functional role of pseudouridylation in mRNA remains unclear.

Upregulation of pseudouridine has been shown to be asso- 
ciated with the progression of various cancers, including prostate cancer (PC), BrC, and HCC (55-58). The nucleolar protein DKC1 plays an important role in two separate cell proliferation pathways: the pseudouridylation of rRNAs, which is necessary for their processing, and the stabilization of the telomerase RNA component that is necessary for telomerase activity (55). Similarly, DKC1 expression is generally upregulated in PC (56, 59). The knockdown of DKC1 by siRNA has been shown to inhibit the proliferation of the e22Rv1, LNCaP, PC3, and Du145 in PC cell lines; however, the knockdown had no significant effects on apoptosis or senescence (56). Moreover, HCC patients with high DKC1 expression have been found to exhibit shorter overall survival rates when compared to those with low DKC1 expression (57). Moreover, elevated DKC1 expression has been shown to positively correlate with MYC oncogene expression, which triggers the expression of target genes to induce cell proliferation and cell survival. In addition, DKC1 expression was shown to induce MKI67 expression, which is considered a marker for cell proliferation $(57,58)$.

However, pseudouridine modification has also been shown to exert negative effects on the development of several types of cancer. Downregulated pseudouridine has been associated with $\mathrm{BrC}$ and $\mathrm{HCC}$ development $(60,61)$. The impairment of DKC1 protein can lead to the inactivation of p53, a wellknown anti-tumor development factor that induces cell cycle arrest or apoptosis, due to abnormal p53 mRNA translation (60). However, low expression of a snoRNA, SNORA24, has been associated with poor survival of patients with steatohepatitic HCC (61). As SNORA24 is known to mediate the psedouridylation of $18 \mathrm{~S}$ rRNA, the depletion of SNORA24 increases the rate of translational miscoding and stop codon read-through frequencies in human HCC (61).

\section{N1-methyladenosine $\left(\mathrm{m}^{\mathbf{1}} \mathrm{A}\right)$}

N1-methyladenosine $\left(\mathrm{m}^{1} \mathrm{~A}\right)$ was first identified in yeast $\mathrm{tRNA} \mathrm{P}^{\mathrm{Phe}}$ and later found to be widespread in tRNAs $(62,63)$. In human cells, the methyltransferases TRMT10C, TRMT61B, and TRMT6/ 61A catalyze $\mathrm{m}^{1} \mathrm{~A}$ at positions 9 and 58 of mitochondrial and cytoplasmic tRNA, respectively (63). $\mathrm{m}^{1} \mathrm{~A}$ modification of tRNA plays a pivotal role in maintaining its proper structure, stability, and function (64-67). Although $\mathrm{m}^{1} \mathrm{~A}$ modification is abundant in tRNA, relatively low levels of modification, ranging from $0.015 \%$ to $0.054 \%$, have been found in mammalian mRNA (68). The majority of $\mathrm{m}^{1} \mathrm{~A}$ modification sites in mRNA are located in the $5^{\prime}$ UTR near the translation start codon (68). TRMT6/61A has been found to localize in the cytoplasm, and contributes to $\mathrm{m}^{1} \mathrm{~A}$ modification in select mRNAs that harbor a tRNA-like motif, GUUCRA (63). As the TRMT6/61A complex seems to play a minor role in $\mathrm{m}^{1} \mathrm{~A}$ mRNA modification, other $\mathrm{m}^{1} \mathrm{~A}$ methyltransferases likely remain to be discovered (63).

Similar to $\mathrm{m}^{6} \mathrm{~A}$ modification, $\mathrm{m}^{1} \mathrm{~A}$ modification is reversible. Demethylation of $\mathrm{m}^{1} \mathrm{~A}$ modification is mediated by $\mathrm{ALKBH} 1$ and $\mathrm{ALKBH} 3(65,66)$. Interestingly, the $\mathrm{m}^{6} \mathrm{~A}$ reader proteins, YTHDF2 and YTHDF3, have also been implicated in the recognition of $m^{1} A$ mRNA modifications $(16,69)$. Reminiscent of $\mathrm{m}^{6} \mathrm{~A}$ modification, $\mathrm{m}^{1} \mathrm{~A}$-modified mRNA undergoes rapid degradation upon binding with YTHDF2 or YTHDF3 $(16,69)$.

To date, several studies have reported a positive correlation between $\mathrm{m}^{1} \mathrm{~A}$ tRNA modification and cancer development. Elevated expression levels of both TRMT6/61A and initiator methionine tRNA ( $\mathrm{tRNA} \mathrm{i}^{\text {Met }}$ ) have been detected in highly aggressive GBM compared with grade II/III gliomas (67). Depletion of the TRMT6/61A complex suppresses proliferation and promotes cell death in $\mathrm{C} 6$ glioma cells, which can be rescued in part by $\mathrm{tRNA}_{\mathrm{i}}^{\text {Met }}$ overexpression (67). Conversely, the ectopic expression of TRMT6/61A has been shown to upregulate the translation of oncogenic mRNAs, leading to increased colonization of C6 glioma cells (67). Similarly, ALKBH1-mediated demethylation of $\mathrm{m}^{1} \mathrm{~A}$ modified tRNA attenuates translation initiation and elongation in HeLa cells, thereby reducing cell proliferation (66).

Intriguingly, another $\mathrm{m}^{1} \mathrm{~A}$ demethylase, $\mathrm{ALKBH} 3$, has been shown to induce an opposite effect to that of $A L K B H 1$ in $\mathrm{m}^{1} \mathrm{~A}$ tRNA modification (70). ALKBH3-mediated $\mathrm{m}^{1} \mathrm{~A}$ tRNA demethylation increases the susceptibility of tRNA to angiogenin cleavage and generates tRNA-derived small RNAs in various cancer cells during cancer cell proliferation, migration, and invasion (70).

\section{2'-O-methylation (Nm)}

A rather unique RNA modification is mediated via $2^{\prime}$-O-methylation (also known as $\mathrm{Nm}$ or $2^{\prime}-\mathrm{O}-\mathrm{me}$ ). $\mathrm{Nm}$ can occur in any nucleotide via the addition of a methyl group to the $2^{\prime}$ hydroxyl of the ribose moiety (71). Nm is an abundant RNA modification that occurs in multiple RNA species, including tRNA, rRNA, snRNA, and mRNA (71-73). Nm modification sites in mRNA are mostly located within the coding sequence (CDS) regions (73). Interestingly, $\mathrm{Nm}$ modification is also found in approximately $16.2 \%$ of introns, suggesting that $\mathrm{Nm}$ modification occurs in the nucleus prior to splicing events (73). In higher eukaryotes, $\mathrm{Nm}$ modification occurs specifically in the first nucleotide [N1] and/or second nucleotide [N2] next to the $\mathrm{m}^{7} \mathrm{G}$-cap of mRNA (74). While $\mathrm{N} 1$ methylation occurs in almost all mRNA molecules, N2 methylation accounts for about half of the capped mRNA. Additional $\mathrm{m}^{6} \mathrm{~A}$ methylation following $\mathrm{Nm}$ leads to $\mathrm{m}^{6} \mathrm{Am}$ formation. Two conserved $\mathrm{Nm}$ writer proteins have been discovered for $\mathrm{N} 1$ and $\mathrm{N} 2$ methylation. FTSJ2 (also known as hMTr1) is responsible for the methylation of N1, whereas FTS 1 (also known as hMTr2) contributes to N2 methylation (75, 76). FTSJ2 also methylates mitochondrial $23 \mathrm{~S}$ rRNA (77). Another $\mathrm{Nm}$ writer protein, fibrillarin $(\mathrm{FBL})$, is an essential nucleolar protein that catalyzes the $\mathrm{Nm}$ of rRNA by interacting with a C/D box family member of U3 snoRNA that mediates the processing of precursor rRNA (74). Given that more than $70 \%$ of all Nm occurs in the CDS regions of mRNA and that known $\mathrm{Nm}$ writers have not been associated with CDS methylation, further studies are needed to identify additional $\mathrm{Nm}$ methyltransferases. $\mathrm{Nm}$ readers and 
erasers also remain unknown.

Many studies suggest that $\mathrm{FBL}$ expression is abnormally high in various cancers, including $\mathrm{PC}$ and $\mathrm{BrC}$ (78-80). One report suggested that a p53 mutation fails to suppress transcription of the $F B L$ gene, resulting in the overexpression of $F B L(80)$. Another report suggested that the MYC protein directly regulates the transcription of $F B L$ by binding to the promoter region of this gene (78). The elevated level of FBL expression has been shown to be associated with a higher transcriptional activity of RNA polymerase I, thus increasing rRNA production $(74,80)$. As increased rRNA biogenesis has been observed in various cancer cells, it is not surprising that many cancers appear to be related to FBL-mediated rRNA production. Indeed, depletion of $\mathrm{FBL}$ has been shown to significantly inhibit tumorigenesis in $\mathrm{PC}$ and $\operatorname{BrC}(79,80)$. In contrast, increased FBL expression not only induces high levels of rRNA synthesis, but also promotes rRNA $\mathrm{Nm}$ that regulates ribosomal quality $(74,80)$. Altered rRNA Nm patterns have been shown to be associated with a decrease in translational fidelity (i.e., increased nonsense suppression, frame-shifts, and mis-incorporation) and increased internal ribosome entry site (IRES)-dependent translation initiation of key cancer genes $(74,80)$. In case of another $\mathrm{Nm}$ methyltransferase, only one report indicated that the increased expression of FTSJ2 was positively correlated with cell proliferation in lung cancer cell lines (77). To date, a negative correlation between $\mathrm{Nm}$ and cancer has not been reported. Furthermore, since reversible $\mathrm{Nm}$ has not been reported, it may be important for cells to maintain $\mathrm{Nm}$ levels below the cancer initiation threshold.

\section{N5-methylcytosine $\left(\mathrm{m}^{5} \mathrm{C}\right)$}

N5-methylcytosine was originally found in ncRNA, including tRNA and rRNA, and subsequently in most RNA species (81, 82). More than $10,000 \mathrm{~m}^{5} \mathrm{C}$ modification sites have been discovered in human mRNA and ncRNA (81). $\mathrm{m}^{5} \mathrm{C}$ modifications have been found to be enriched in the $5^{\prime}$ UTRs and $3^{\prime}$ UTRs of mRNA (81). Recently, a study reported that $\mathrm{m}^{5} \mathrm{C}$ modifications are enriched in CG-rich regions and immediately downstream of translation initiation regions of mRNA in multiple mice tissues (82). In rRNA, $\mathrm{m}^{5} \mathrm{C}$ modification sites have been shown to be fairly conserved, and both the small and large subunits of rRNA in bacteria and eukaryotes harbor $\mathrm{m}^{5} \mathrm{C}$ methylation sites at similar positions (83). Although several $\mathrm{m}^{5} \mathrm{C}$ locations have been identified in human $28 \mathrm{~S}$ rRNA, the functional roles of these sites remain unclear (83). Several $\mathrm{m}^{5} \mathrm{C}$ modification writer proteins have been identified, including members of the NOL1/NOP2/Sun (NSUN)-domain-containing family (from NSUN1 to NSUN7) and DNA methyltransferase 2 (DNMT2) families (84). Initially, NSUN2 was thought to be responsible for $\mathrm{m}^{5} \mathrm{C}$ modification of $\mathrm{tRNA}$, but was later found to also methylate many RNA species, including tRNA, mRNA, and miRNA $(81,82,85)$. tRNA methyltransferase 1 (TRDMT1), a member of the DNMT2 family, is primarily responsible for the $\mathrm{m}^{5} \mathrm{C}$ modification of tRNA and mRNA (86). tRNA $\mathrm{m}^{5} \mathrm{C}$ methylation mediated by either TRDMT1 or NSUN2 increases tRNA stability and protein synthesis (87). Other members of the NSUN family have been associated with $\mathrm{m}^{5} \mathrm{C}$ modification in enhancer RNA, rRNA, mitochondrial tRNA (mt-tRNA), or mt-rRNA (88). In the two protein families, NSUN2 and DNMT2 are known to be associated with malignant cancer. Although an $\mathrm{m}^{5} \mathrm{C}$ eraser protein has not been identified, Aly/REF, an mRNA export adapter protein complex, has been found to act as a novel $\mathrm{m}^{5} \mathrm{C}$ reader protein that methylates mRNA in CG-rich sequences and in translation initiation regions (82). A recent study identified Y-box-binding protein 1 (YBX1) as a reader protein that recognizes $\mathrm{m}^{5} \mathrm{C}$ modification and maintains the stability of the target mRNA (89).

A few studies have investigated the effects of $\mathrm{m}^{5} \mathrm{C}$ on tumorigenesis. It has been identified that NSUN2 protein is a downstream target of MYC that methylates RNA polymerase III transcripts (85). Elevated expression of NSUN2 has been shown to mediate MYC-induced cell proliferation and growth in squamous cell carcinoma and $\operatorname{BLC}(85,89)$. Moreover, HDGF mRNA has been reported to undergo $\mathrm{m}^{5} \mathrm{C}$ modification in the $3^{\prime}$ UTR and is stabilized by YBX1, increasing HDGF protein synthesis (89). This finding was consistent with those of another study showing that reduced survival of BLC patients was correlated with increased expression of NSUN2 and HDGF (89). Another $\mathrm{m}^{5} \mathrm{C}$ methyltransferase, TRDMT1, is also correlated with cell proliferation and migration and gene ontology (GO) analyses have shown that the depletion of TRDMT1 leads to altered expression of genes associated with the regulation of the cell cycle, RNA transport, and RNA degradation (90).

While few studies have reported a correlation between $\mathrm{m}^{5} \mathrm{C}$ modification and cancer, it will be informative to consider the effects of $\mathrm{m}^{5} \mathrm{C}$ on the regulation of translation, given that $\mathrm{m}^{5} \mathrm{C}$ modifications occur mainly in $5^{\prime}$ or $3^{\prime}$ UTRs.

\section{Internal $N 7$-methylguanosine $\left(\mathrm{m}^{7} \mathrm{G}\right)$}

N7-methylguanosine $\left(\mathrm{m}^{7} \mathrm{G}\right)$ is the best-known modification in the form of mRNA 5' cap (91). Recently, an internal $\mathrm{m}^{7} \mathrm{G}$ modification was also identified in rRNAs, tRNAs, miRNAs, and mRNAs (92-94). $m^{7} G$ modification is found at the nucleotide position 46 in several tRNA variable loops known to stabilize the tRNA tertiary structure $(95,96)$. In mammalian cells, the internal $\mathrm{m}^{7} \mathrm{G} / \mathrm{G}$ ratio of mRNA ranges from $0.02 \%$ to $0.05 \%$ (94). Internal $\mathrm{m}^{7} \mathrm{G}$ modification has been found to be preferentially enriched in either AG-rich or GA-rich regions in mRNA $(94,95)$ and is mediated by METTL1 and its co-factor, WD repeat domain 4 (WDR4) in mRNA, miRNA, and tRNA $(6,96)$. Specifically, the knockdown of METTL1 has been shown to lead to a global decrease in internal $\mathrm{m}^{7} \mathrm{G}$ modification by approximately $54 \%$ and $61 \%$ in HeLa cells and HepG2 cells, respectively (94). To date, no readers or erasers for $\mathrm{m}^{7} \mathrm{G}$ modification have been identified.

A positive association between internal $\mathrm{m}^{7} \mathrm{G}$ and cancer has yet to be identified. However, internal $\mathrm{m}^{7} \mathrm{G}$ modification of primary miRNA transcripts has been shown to have negative 
effects on lung cancer and colon cancer development. Specifically, the pri-let-7e transcript has been found to be targeted by METTL1 during internal $\mathrm{m}^{7} \mathrm{G}$ modification and generates a mature form of let-7e via efficient processing $(93,97)$. The increased expression of mature let-7e downregulates its target, the high-mobility group AT-hook 2 (HMGA2) mRNA, which is known to drive cancer metastasis $(93,97)$. The association with $\mathrm{m}^{7} \mathrm{G}$ modification is unclear; however, the $\mathrm{m}^{7} \mathrm{G}$ writer protein, METTL1, itself inhibits the PTEN signaling pathway in HCC to promote cell proliferation and migration, resulting in tumor growth and greater tumor vascular invasion (6).

\section{DISCUSSION}

Given the plethora of signaling pathways converging upon gene expression regulatory pathways to satisfy the increased anabolic demands in cancer, a better understanding of the gene regulatory mechanisms controlling tumorigenesis will facilitate their therapeutic exploitation $(5,6,11)$. The field of epitranscriptomics has attracted the attention of various biological investigators in recent years; however, the molecular players and mechanisms underlying epitranscriptome regulation remain to be elucidated. In particular, several studies on the relationship between RNA modification and cancer have been published, many of which either lack data regarding the detailed mechanisms involved or often report contrasting results. For instance, pseudouridine, $\mathrm{m}^{1} \mathrm{~A}, \mathrm{Nm}$, and internal $\mathrm{m}^{7} \mathrm{G}$ modifications have been found in mRNAs across the gene body; however, their roles in mRNA metabolism and their effects on cancer progression remain unknown $(49,65$, $94,95)$. Instead, most published studies have merely investigated the effects of the enzymes catalyzing the modifications on cancers, without confirming the effects of RNA modification. With the exception of $\mathrm{m}^{6} \mathrm{~A}$ and $\mathrm{m}^{1} \mathrm{~A}$, the reversibility of RNA modifications and their specific reader proteins also remain unclear. Moreover, the molecular functions and cellular consequences of $\mathrm{m}^{6} \mathrm{~A}$ or pseudouridine modification often differ across studies, depending on the degree of methylation in the specific target RNAs (Fig. 1).

In addition to the extensive interest in the roles of RNA modification in cancer, the development of potential drugs to treat cancer by modulating RNA modification has also attracted attention (98). However, there are currently no inhibitors or antagonists targeting writer and reader proteins, or the RNA modifications discussed in this review (98). Instead, several inhibitors of demethylases have been suggested. The ALKBH family and FTO share a common structure required for the binding of $\mathrm{Fe}^{2+}$ as a co-factor and 2-oxoglutarate (2OG) as a co-substrate (98). Therefore, most of the known compounds, including 2OG competitors such as $\mathrm{N}$-oxalylglycine and its cell-penetrating derivative dimethyl oxalylglycine, succinate, fumarate, and 2-hydroxyglutarate, or metal chelators such as hydroxamic acids and flavonoids, were designed to target either $\mathrm{Fe}^{2+}$ or $2 \mathrm{OG}$ binding sites $(98,99)$. However, these compounds are still far from being used in anticancer drugs because they nonspecifically inhibit various demethylases. Some specific demethylase inhibitors have also been discovered, such as the ALKBH3 inhibitor, 1-(5-methyl-1H-benzimidazol-2yl)-4-benzyl-3-methyl-1H-pyrazol-5-ol (HUHS015), and FTO inhibitor, Rhein. However, the efficacy of these drugs remains doubtful because of their nonspecificity for target RNAs (98, 99). More recently, clustered regularly interspaced short palindromic repeats (CRISPR) based RNA-editing technology has been suggested for modulating target mRNA specific modifications (100). The CRISPR-associated nuclease Cas13 has been shown to cleave the targeted single-stranded RNA (100). A catalytically inactive mutant of Cas13 (dCas13) fused with $\mathrm{m}^{6} \mathrm{~A}$ methyltransferases METTL3 or METTL14 has been found to bind to the target mRNA specifically directed by the guide RNA, without the cleavage of the mRNA (100). Targeting of these fusion proteins has been shown to specifically methylate adenosine within a small range of target sites, regardless of the $\mathrm{m}^{6} \mathrm{~A}$ consensus sequence (100). Thus, CRISPR-based approaches can be applied not only in the modulation of $\mathrm{m}^{6} \mathrm{~A}$ modifications, but also to other types of RNA modifications. Given the abnormal up/downregulation of modified RNA transcripts and their regulatory proteins in cancer, the development of this technology will shed more light on the feasibility of controlling the modification of RNA targets for cancer treatment. Taken together, the analysis presented in this review highlights the need to further elucidate the mechanisms of RNA modification-mediated regulation of gene expression to improve cancer therapy.

\section{ACKNOWLEDGEMENTS}

This work was supported by the National Research Foundation of Korea (NRF) grant funded by the Korea government (Ministry of Science and ICT) (NRF-2020R1C1C1009842 and NRF- 2020R1A4A1018398).

\section{CONFLICTS OF INTEREST}

The authors have no conflicting interests.

\section{REFERENCES}

1. Zhou S, Treloar AE and Lupien M (2016) Emergence of the noncoding cancer genome: a target of genetic and epigenetic alterations. Cancer Discovery 6, 1215-1229

2. Chiba T, Marusawa H and Ushijima T (2012) Inflammation-associated cancer development in digestive organs: mechanisms and roles for genetic and epigenetic modulation. Gastroenterology 143, 550-563

3. Yu K, Xiang L, Li S, Wang S, Chen C and Mu H (2019) HIF1alpha promotes prostate cancer progression by increasing ATG5 expression. Anim Cells Syst (Seoul) 23, 326-334

4. Heard E and Martienssen RA (2014) Transgenerational 
epigenetic inheritance: myths and mechanisms. Cell 157, 95-109

5. Zhao Y, Zhao Q, Kaboli PJ et al (2019) m1A regulated genes modulate PI3K/AKT/mTOR and ErbB pathways in gastrointestinal cancer. Transl Oncol 12, 1323-1333

6. Tian QH, Zhang MF, Zeng JS et al (2019) METTL1 overexpression is correlated with poor prognosis and promotes hepatocellular carcinoma via PTEN. J Mol Med 97, 1535-1545

7. Yu FX, Zhao B and Guan KL (2015) Hippo pathway in organ size control, tissue homeostasis, and cancer. Cell $163,811-828$

8. Meyer KD, Saletore Y, Zumbo P, Elemento O, Mason CE and Jaffrey SR (2012) Comprehensive analysis of mRNA methylation reveals enrichment in $3^{\prime}$ UTRs and near stop codons. Cell 149, 1635-1646

9. Helm M and Motorin Y (2017) Detecting RNA modifications in the epitranscriptome: predict and validate. Nat Rev Genet 18, 275-291

10. Zhao BS, Roundtree IA and He C (2018) Publisher correction: Post-transcriptional gene regulation by mRNA modifications. Nat Rev Mol Cell Biol 19, 808

11. Fu Y, Dominissini D, Rechavi G and He C (2014) Gene expression regulation mediated through reversible $\mathrm{m}(6) \mathrm{A}$ RNA methylation. Nat Rev Genet 15, 293-306

12. Boccaletto P, Machnicka MA, Purta E et al (2018) MODOMICS: a database of RNA modification pathways. 2017 update. Nucleic Acids Res 46, D303-D307

13. Zhang ZJ, Park E, Lin L and Xing Y (2018) A panoramic view of RNA modifications: exploring new frontiers. Genome Biol 19, 11

14. Shi H, Wei J and He C (2019) Where, when, and how: context-dependent functions of RNA methylation writers, readers, and erasers. Mol Cell 74, 640-650

15. Zuo XL, Chen ZQ, Gao W et al (2020) M6A-mediated upregulation of LINC00958 increases lipogenesis and acts as a nanotherapeutic target in hepatocellular carcinoma. J Hematol Oncol 13, 5

16. Zheng QL, Gan HL, Yang FL et al (2020) Cytoplasmic $\mathrm{m}(1) \mathrm{A}$ reader YTHDF3 inhibits trophoblast invasion by downregulation of m(1)A-methylated IGF1R. Cell Discov 6, 12

17. Nachtergaele S and He C (2018) Chemical modifications in the life of an mRNA transcript. Annu Rev Genet 52, 349-372

18. Dominissini D, Moshitch-Moshkovitz S, Schwartz S et al (2012) Topology of the human and mouse m6A RNA methylomes revealed by m6A-seq. Nature 485, 201-206

19. Linder B, Grozhik AV, Olarerin-George AO, Meydan C, Mason CE and Jaffrey SR (2015) Single-nucleotide-resolution mapping of $\mathrm{m} 6 \mathrm{~A}$ and $\mathrm{m} 6 \mathrm{Am}$ throughout the transcriptome. Nat Methods 12, 767-772

20. Xiao S, Cao S, Huang Q et al (2019) The RNA N(6)methyladenosine modification landscape of human fetal tissues. Nat Cell Biol 21, 651-661

21. Wang P, Doxtader KA and Nam Y (2016) Structural basis for cooperative function of Mettl3 and Mettl14 methyltransferases. Mol Cell 63, 306-317

22. Wen J, Lv R, Ma H et al (2018) Zc3h13 regulates nuclear RNA m(6)A methylation and mouse embryonic stem cell self-renewal. Mol Cell 69, 1028-1038 e1026

23. Ping XL, Sun BF, Wang L et al (2014) Mammalian WTAP is a regulatory subunit of the RNA N6-methyladenosine methyltransferase. Cell Res 24, 177-189

24. Patil DP, Chen CK, Pickering BF et al (2016) m(6)A RNA methylation promotes XIST-mediated transcriptional repression. Nature 537, 369-373

25. Jia G, Fu Y, Zhao X et al (2011) N6-methyladenosine in nuclear RNA is a major substrate of the obesity-associated FTO. Nat Chem Biol 7, 885-887

26. Zheng G, Dahl JA, Niu Y et al (2013) ALKBH5 is a mammalian RNA demethylase that impacts RNA metabolism and mouse fertility. Mol Cell 49, 18-29

27. Wei J, Liu F, Lu Z et al (2018) Differential m(6)A, $\mathrm{m}(6) \mathrm{Am}$, and $\mathrm{m}(1) \mathrm{A}$ demethylation mediated by FTO in the cell nucleus and cytoplasm. Mol Cell 71, 973-985 e975

28. Wang Y, Li Y, Toth JI, Petroski MD, Zhang Z and Zhao JC (2014) N6-methyladenosine modification destabilizes developmental regulators in embryonic stem cells. Nat Cell Biol 16, 191-198

29. Huang $H$, Weng $H$, Sun $W$ et al (2018) Recognition of RNA N(6)-methyladenosine by IGF2BP proteins enhances mRNA stability and translation. Nat Cell Biol 20, 285295

30. Wang X, Zhao BS, Roundtree IA et al (2015) N(6)-methyladenosine modulates messenger RNA translation efficiency. Cell 161, 1388-1399

31. Shi H, Wang X, Lu Z et al (2017) YTHDF3 facilitates translation and decay of $\mathrm{N}(6)$-methyladenosine-modified RNA. Cell Res 27, 315-328

32. Liu N, Dai Q, Zheng G, He C, Parisien M and Pan $T$ (2015) N(6)-methyladenosine-dependent RNA structural switches regulate RNA-protein interactions. Nature 518, 560-564

33. Meyer KD, Patil DP, Zhou J et al (2015) 5' UTR m(6)A promotes cap-independent translation. Cell 163, 999-1010

34. Choe J, Lin S, Zhang W et al (2018) mRNA circularization by METTL3-elF3h enhances translation and promotes oncogenesis. Nature 561, 556-560

35. Lin S, Choe J, Du P, Triboulet R and Gregory RI (2016) The $\mathrm{m}(6) \mathrm{A}$ methyltransferase METTL3 promotes translation in human cancer cells. Mol Cell 62, 335-345

36. Han SH and Choe J (2020) Diverse molecular functions of $\mathrm{m}(6) \mathrm{A}$ mRNA modification in cancer. Exp Mol Med 52, 738-749

37. Fazi F and Fatica A (2019) Interplay between N (6)-methyladenosine $(\mathrm{m}(6) \mathrm{A})$ and non-coding RNAs in cell development and cancer. Front Cell Dev Biol 7, 116

38. Sun T, Wu R and Ming $L$ (2019) The role of m6A RNA methylation in cancer. Biomed Pharmacother 112, 108613

39. Chen $X Y$, Zhang J and Zhu JS (2019) The role of $m(6) A$ RNA methylation in human cancer. Mol Cancer 18, 103

40. Wang Q, Chen C, Ding Q et al (2020) METTL3-mediated $\mathrm{m}(6) \mathrm{A}$ modification of HDGF mRNA promotes gastric cancer progression and has prognostic significance. Gut 69, 1193-1205

41. Li T, Hu PS, Zuo Z et al (2019) METTL3 facilitates tumor progression via an m(6)A-IGF2BP2-dependent mechanism in colorectal carcinoma. Mol Cancer 18, 112

42. Jin H, Ying X, Que B et al (2019) N(6)-methyladenosine 
modification of ITGA6 mRNA promotes the development and progression of bladder cancer. EBioMedicine 47, 195-207

43. Barbieri I, Tzelepis K, Pandolfini L et al (2017) Promoterbound METTL3 maintains myeloid leukaemia by m(6)Adependent translation control. Nature 552, 126-131

44. Han J, Wang JZ, Yang X et al (2019) METTL3 promote tumor proliferation of bladder cancer by accelerating pri-miR221/222 maturation in m6A-dependent manner. Mol Cancer 18, 110

45. Chen XX, Xu M, Xu XN et al (2020) METTL14-mediated N6-methyladenosine modification of SOX4 mRNA inhibits tumor metastasis in colorectal cancer. Mol Cancer 19,106

46. Gu CH, Wang ZY, Zhou NC et al (2019) Mettl14 inhibits bladder TIC self-renewal and bladder tumorigenesis through $\mathrm{N}-6-$-methyladenosine of Notch1. Mol Cancer 18, 168

47. Yang X, Zhang S, He C et al (2020) METTL14 suppresses proliferation and metastasis of colorectal cancer by down-regulating oncogenic long non-coding RNA XIST. Mol Cancer 19, 46

48. Cohn WE and Volkin E (1951) Nucleoside-5'-phosphates from ribonucleic acid. Nature 167, 483-484

49. Schwartz S, Bernstein DA, Mumbach MR et al (2014) Transcriptome-wide mapping reveals widespread dynamic-regulated pseudouridylation of ncRNA and mRNA. Cell 159, 148-162

50. Li X, Zhu P, Ma S et al (2015) Chemical pulldown reveals dynamic pseudouridylation of the mammalian transcriptome. Nat Chem Biol 11, 592-597

51. Hoang C and Ferre-D'Amare AR (2001) Cocrystal structure of a tRNA Psi55 pseudouridine synthase: nucleotide flipping by an RNA-modifying enzyme. Cell 107, 929-939

52. De Zoysa MD and Yu YT (2017) Posttranscriptional RNA Pseudouridylation. Enzymes 41, 151-167

53. Duan J, Li L, Lu J, Wang W and Ye K (2009) Structural mechanism of substrate RNA recruitment in H/ACA RNA-guided pseudouridine synthase. Mol Cell 34, 427439

54. Rintala-Dempsey AC and Kothe U (2017) Eukaryotic standalone pseudouridine synthases - RNA modifying enzymes and emerging regulators of gene expression? RNA Biol $14,1185-1196$

55. Montanaro L, Brigotti M, Clohessy J et al (2006) Dyskerin expression influences the level of ribosomal RNA pseudo-uridylation and telomerase RNA component in human breast cancer. J Pathol 210, 10-18

56. Sieron P, Hader C, Hatina J et al (2009) DKC1 overexpression associated with prostate cancer progression. $\mathrm{Br}$ J Cancer 101, 1410-1416

57. Liu B, Zhang J, Huang C and Liu H (2012) Dyskerin overexpression in human hepatocellular carcinoma is associated with advanced clinical stage and poor patient prognosis. PLoS One 7, e43147

58. Alawi F, Lin P, Ziober B and Patel R (2011) Correlation of dyskerin expression with active proliferation independent of telomerase. Head Neck 33, 1041-1051

59. Stockert JA, Gupta A, Herzog B, Yadav SS, Tewari AK and Yadav KK (2019) Predictive value of pseudouridine in prostate cancer. Am J Clin Exp Urol 7, 262-272

60. Montanaro L, Calienni M, Bertoni S et al (2010) Novel dyskerin-mediated mechanism of p53 inactivation through defective mRNA translation. Cancer Res 70, 4767-4777

61. McMahon M, Contreras A, Holm M et al (2019) A single H/ACA small nucleolar RNA mediates tumor suppression downstream of oncogenic RAS. Elife 8, e48847

62. RajBhandary UL, Stuart A, Faulkner RD, Chang SH and Khorana HG (1966) Nucleotide sequence studies on yeast phenylalanine sRNA. Cold Spring Harb Symp Quant Biol 31, 425-434

63. Li X, Xiong X, Zhang $M$ et al (2017) Base-resolution mapping reveals distinct $\mathrm{m}(1) \mathrm{A}$ methylome in nuclearand mitochondrial-encoded transcripts. Mol Cell 68, 9931005 e1009

64. Roundtree IA, Evans ME, Pan T and He C (2017) Dynamic RNA modifications in gene expression regulation. Cell $169,1187-1200$

65. Li X, Xiong X, Wang K et al (2016) Transcriptome-wide mapping reveals reversible and dynamic N(1)-methyladenosine methylome. Nat Chem Biol 12, 311-316

66. Liu FG, Clark W, Luo GZ et al (2016) ALKBH1-mediated tRNA demethylation regulates translation. Cell 167, 816-828. e16

67. Macari F, El-Houfi Y, Boldina G et al (2016) TRM6/61 connects PKCalpha with translational control through tRNAi(Met) stabilization: impact on tumorigenesis. Oncogene 35, 1785-1796

68. Dominissini D, Nachtergaele S, Moshitch-Moshkovitz S et al (2016) The dynamic N(1)-methyladenosine methylome in eukaryotic messenger RNA. Nature 530, 441-446

69. Seo KW and Kleiner RE (2020) YTHDF2 Recognition of $\mathrm{N}$-1-methyladenosine $(\mathrm{m}(1) \mathrm{A})$-modified RNA is associated with transcript destabilization. Acs Chemical Biol 15, 132139

70. Chen Z, Qi M, Shen B et al (2019) Transfer RNA demethylase ALKBH3 promotes cancer progression via induction of tRNA-derived small RNAs. Nucleic Acids Res 47, 2533-2545

71. Somme J, Van Laer B, Roovers M, Steyaert J, Versees W and Droogmans L (2014) Characterization of two homologous 2'-O-methyltransferases showing different specificities for their tRNA substrates. RNA 20, 1257-1271

72. Rebane A, Roomere H and Metspalu A (2002) Locations of several novel 2'-O-methylated nucleotides in human $28 \mathrm{~S}$ rRNA. BMC Mol Biol 3, 1

73. Dai Q, Moshitch-Moshkovitz S, Han DL et al (2017) $\mathrm{Nm}$-seq maps 2'-O-methylation sites in human mRNA with base precision (vol 14, pg 695, 2017). Nat Methods $15,226-227$

74. Dimitrova DG, Teysset L and Carre C (2019) RNA 2'-O-methylation $(\mathrm{Nm})$ modification in human diseases. Genes (Basel) 10, 117

75. Belanger F, Stepinski J, Darzynkiewicz E and Pelletier J (2010) Characterization of hMTr1, a human Cap1 2'-Oribose methyltransferase. J Biol Chem 285, 33037-33044

76. Werner M, Purta E, Kaminska KH et al (2011) 2'-Oribose methylation of cap2 in human: function and evolution in a horizontally mobile family. Nucleic Acids Res 
39, 4756-4768

77. Ching YP, Zhou HJ, Yuan JG, Qiang BQ, Kung Hf HF and Jin DY (2002) Identification and characterization of FTSJ2, a novel human nucleolar protein homologous to bacterial ribosomal RNA methyltransferase. Genomics $79,2-6$

78. Koh CM, Gurel B, Sutcliffe S et al (2011) Alterations in nucleolar structure and gene expression programs in prostatic neoplasia are driven by the MYC oncogene. Am J Pathol 178, 1824-1834

79. Su H, Xu T, Ganapathy $\mathrm{S}$ et al (2014) Elevated snoRNA biogenesis is essential in breast cancer. Oncogene 33, 1348-1358

80. Marcel V, Ghayad SE, Belin S et al (2013) p53 acts as a safeguard of translational control by regulating fibrillarin and rRNA methylation in cancer. Cancer Cell 24, 318330

81. Squires JE, Patel HR, Nousch M et al (2012) Widespread occurrence of 5-methylcytosine in human coding and non-coding RNA. Nucleic Acids Res 40, 5023-5033

82. Yang X, Yang Y, Sun BF et al (2017) 5-methylcytosine promotes mRNA export-NSUN2 as the methyltransferase and ALYREF as an $\mathrm{m}(5) \mathrm{C}$ reader. Cell Res 27, 606625

83. Motorin Y, Lyko F and Helm M (2010) 5-methylcytosine in RNA: detection, enzymatic formation and biological functions. Nucleic Acids Res 38, 1415-1430

84. Bohnsack KE, Hobartner C and Bohnsack MT (2019) Eukaryotic 5-methylcytosine $(\mathrm{m}(5) \mathrm{C})$ RNA methyltransferases: mechanisms, cellular functions, and links to disease. Genes (Basel) 10, 102

85. Frye M and Watt FM (2006) The RNA methyltransferase Misu (NSun2) mediates Myc-induced proliferation and is upregulated in tumors. Current Biol 16, 971-981

86. Goll MG, Kirpekar F, Maggert KA et al (2006) Methylation of tRNAAsp by the DNA methyltransferase homolog Dnmt2. Science 311, 395-398

87. Tuorto F, Liebers R, Musch T et al (2012) RNA cytosine methylation by Dnmt2 and NSun2 promotes tRNA stability and protein synthesis. Nat Struct Mol Biol 19, 900-905

88. Trixl L and Lusser A (2019) The dynamic RNA modification 5-methylcytosine and its emerging role as an epitranscriptomic mark. Wiley Interdiscip Rev RNA 10, e1510

89. Chen X, Li A, Sun BF et al (2019) 5-methylcytosine promotes pathogenesis of bladder cancer through stabilizing mRNAs. Nat Cell Biol 21, 978-990

90. Xue S, Xu H, Sun Z et al (2019) Depletion of TRDMT1 affects 5-methylcytosine modification of mRNA and inhibits HEK293 cell proliferation and migration. Biochem Biophys Res Commun 520, 60-66

91. Ramanathan A, Robb GB and Chan SH (2016) mRNA capping: biological functions and applications. Nucleic Acids Res 44, 7511-7526

92. Tomikawa C (2018) 7-methylguanosine modifications in transfer RNA (tRNA). Int J Mol Sci 19, 4080

93. Pandolfini L, Barbieri I, Bannister AJ et al (2019) METTL1 promotes let-7 microRNA processing via $\mathrm{m} 7 \mathrm{G}$ methylation. Mol Cell 74, 1278-1290 e1279

94. Zhang LS, Liu C, Ma HH et al (2019) Transcriptomewide mapping of internal $\mathrm{N}$-7-methylguanosine methylome in mammalian mRNA. Mol Cell 74, 1304-1316.e8

95. Malbec L, Zhang T, Chen YS et al (2019) Dynamic methylome of internal mRNA N-7-methylguanosine and its regulatory role in translation. Cell Res 29, 927-941

96. Alexandrov A, Martzen MR and Phizicky EM (2002) Two proteins that form a complex are required for 7-methylguanosine modification of yeast tRNA. RNA 8, 1253-1266

97. Liu Y, Zhang YS, Chi Q, Wang Z and Sun BS (2020) Methyltransferase-like 1 (METTL1) served as a tumor suppressor in colon cancer by activating 7-methyguanosine (m7G) regulated let-7e miRNA/HMGA2 axis. Life Sci 249, 117480

98. Uddin MB, Wang Z and Yang C (2020) Dysregulations of functional RNA modifications in cancer, cancer stemness and cancer therapeutics. Theranostics 10, 3164-3189

99. Niu Y, Wan A, Lin Z, Lu X and Wan G (2018) N (6)-methyladenosine modification: a novel pharmacological target for anti-cancer drug development. Acta Pharm Sin B 8, 833-843

100. Wilson C, Chen PJ, Miao Z and Liu DR (2020) Programmable $\mathrm{m}(6) \mathrm{A}$ modification of cellular RNAs with a Cas13-directed methyltransferase. Nat Biotechnol 38, 14311440 